\title{
INFLUÊNCIA DA ADIÇÃO DE ESPESSANTES E LEITE EM PÓ NAS CARACTERÍSTICAS REOLÓGICAS DO IOGURTE DESNATADO
}

\author{
CAMILA DUARTE TELES* \\ SIMONE HICKMAN FLÔRES**
}

\begin{abstract}
A demanda por produtos lácteos com teor reduzido de gordura aumentou em função da consciência dos efeitos nocivos da gordura na saúde humana. Entretanto, o iogurte desnatado apresenta baixa viscosidade, sendo recomendável o uso de espessantes para conferir e manter as características desejáveis de textura e corpo. Neste trabalho utilizouse a metodologia da superfície de resposta para estudar a influência da adição de leite em pó desnatado, gelatina, goma xantana e goma guar nas características reológicas do iogurte natural desnatado. As variáveis que mais influenciaram a viscosidade foram gelatina, goma guar, goma xantana e a interação leite em pó - gelatina $(p<0,05)$, respectivamente. Além disso, alguns tratamentos apresentaram comportamento de fluido tipo HerschelBulkley e outros de fluido pseudoplástico.
\end{abstract}

PALAVRAS-CHAVE: IOGURTE DESNATADO; REOLOGIA; METODOLOGIA DA SUPERFÍCIE DE RESPOSTA.

* Engenheira de Alimentos, Mestre em Engenharia de Produção, Universidade Federal do Rio Grande do Sul (UFRGS), Porto Alegre, RS (e-mail: camilateles@producao.ufrgs.br).

** Engenheira Química, UFRGS, Porto Alegre, RS (e-mail: simone.flores@ufrgs.br). 


\section{INTRODUÇÃO}

A legislação brasileira define iogurte como sendo o produto resultante da fermentação do leite pasteurizado, ou esterilizado, cuja fermentação se realiza com cultivos de Streptococcus salivarius subsp. thermophilus e Lactobacillus delbrueckii subsp. bulgaricus. O uso de aditivos é proibido na elaboração de leites fermentados, excetuando-se a classe "desnatados" que pode conter aditivos espessantes e/ou estabilizantes em quantidades máximas estabelecidas (BRASIL, 2000).

A consciência dos efeitos nocivos da gordura na saúde humana tem aumentado a demanda por produtos lácteos com teor reduzido ou sem gordura. As dietas com altas quantidades de gordura favorecem o desenvolvimento da obesidade, de alguns tipos de câncer, de distúrbios digestivos e de diabete. Além disso, a ingestão de ácidos graxos saturados está associada ao aumento do colesterol sangüíneo e das doenças coronarianas (AKOH, 1998; ÜNAL, METIN e ISIKLI, 2003).

A baixa viscosidade do iogurte desnatado originou inúmeras pesquisas visando melhorar a textura e o corpo dos iogurtes com teor reduzido de gordura. Dentre essas podem ser citados trabalhos sobre o uso de culturas starters especiais que produzem exopolissacarídeos (RUASMADIEDO e ZOON, 2003; FOLKENBERG et al., 2006), o estudo do leite submetido a altas pressões (ANCOS et al., 2000; LANCIOTTI et al., 2004), a influência do tratamento térmico no comportamento reológico do gel do iogurte (LUCEY, MUNRO e SINGH 1999) e o efeito da adição de substitutos de gordura (como espessantes e derivados de soro de queijo) nas características reológicas, físicoquímicas e sensoriais do iogurte (EVERETT e MCLEOD, 2005; EL-SAYED et al., 2002; ÜNAL, METIN e ISIKLI, 2003; KOKSOY e KILIC, 2004).

Os espessantes usados em produtos lácteos têm como principal função realçar, atribuir e manter as características desejáveis de corpo como, textura, viscosidade e aparência, melhorando os atributos sensoriais do produto final (KOKSOY e KILIC, 2004). Os espessantes e geleificantes mais utilizados em iogurtes são: gelatina, alginatos, carboximetilcelulose, carragenas, pectinas com baixa e alta metoxilação, amidos, amidos modificados, ágar, goma locuste, goma xantana e goma guar (ÜNAL, METIN e ISIKLI, 2003; KOKSOY e KILIC, 2004)

A determinação das propriedades reológicas dos alimentos auxilia o controle de qualidade dos produtos e propicia melhor entendimento de sua estrutura, além de ser necessária no cálculo de qualquer processo que envolva escoamento de fluido (RAO, 1994; MARCOTTE, HOSHAHILI e RAMASWAMY, 2001; ÜNAL, METIN e ISIKI, 2003).

O objetivo deste trabalho foi avaliar a influência da concentração de leite em pó desnatado, gelatina, goma xantana e goma guar nas características reológicas de iogurte natural desnatado classificando-o (dentre os tipos de fluidos existentes) de acordo com a quantidade e o tipo de espessantes utilizados.

\section{MATERIAL E MÉTODOS}

\subsection{PREPARO DO IOGURTE}

Em todos os experimentos foram utilizados $950 \mathrm{~mL}$ de leite tipo $C$ desnatado, sendo $50 \mathrm{~mL}$ desses adicionados na forma de inóculo. Os constituintes sólidos (soro de leite em pó, leite em pó, gelatina, goma xantana e goma guar) foram pesados e misturados no leite até a obtenção de líquido homogêneo. A seguir, a mistura foi aquecida até a temperatura de $80^{\circ} \mathrm{C}$ durante 10 minutos e resfriada até $40^{\circ} \mathrm{C}$.

Para a fermentação do iogurte utilizou-se o fermento lácteo para preparo de iogurte natural $\mathrm{RICH}^{\circledast}$, constituído de culturas superconcentradas de L. bulgaricus e S. thermophilus (fabricado pela Chr. Hansen A/S). O inóculo consistiu de $1 \mathrm{~g}$ de fermento homogeneizado em $1 \mathrm{~L}$ de leite tipo $\mathrm{C}$ integral fervido e resfriado até a temperatura de $40^{\circ} \mathrm{C}$, sendo posteriormente incubado por uma hora. $\mathrm{O}$ inóculo foi adicionado à mistura e essa incubada em estufa na temperatura de $44^{\circ} \mathrm{C}$. Marcouse o término da fermentação quando a acidez de $70^{\circ}$ Dornic era atingida, sendo o iogurte resfriado. A acidez foi determinada conforme metodologia proposta por TRONCO (1997). 


\subsection{DETERMINAÇÃO DAS CARACTERÍSTICAS REOLÓGICAS}

As curvas de reologia foram determinadas em viscosímetro Brookfield digital, modelo DV-I+, com adaptador para amostras de pequeno volume. Utilizou-se o spindle número 21 e variou-se a velocidade angular entre 0,5 e $100 \mathrm{rpm}(0,5 ; 1,0 ; 2,0 ; 2,5 ; 4,0 ; 5,0 ; 10 ; 20 ; 50 ; 100 \mathrm{rpm})$, permanecendo durante 40 segundos em cada velocidade sem controle de temperatura. A temperatura inicial das amostras foi de $10^{\circ} \mathrm{C}$ (BROOKFIELD..., 1992).

Para a determinação do tipo de comportamento reológico dos tratamentos utilizou-se o software Curve Expert 1.3. Os resultados de viscosidade utilizados no planejamento experimental foram determinados na velocidade angular de 4 rpm, spindle 21 após 40 segundos (HYAMS, 19997).

\subsection{PLANEJAMENTO EXPERIMENTAL}

Usou-se planejamento fatorial $2^{4} \mathrm{com}$ oito pontos axiais e três pontos centrais, totalizando 27 ensaios. A Tabela 1 apresenta os valores reais e codificados das variáveis: leite em pó $\left(x_{1}\right)$, gelatina $\left(x_{2}\right)$, goma xantana $\left(x_{3}\right)$ e goma guar $\left(x_{4}\right)$ para os 27 tratamentos. Os resultados foram analisados pela metodologia da superfície de resposta, utilizando-se como ferramenta o software Statistica 5.0. O polinômio empregado para ajuste do modelo foi:

$$
Y=b_{o}+\sum_{i=1}^{4} b_{i} x_{i}+\sum_{i=1}^{4} b_{i i} x_{i}^{2} \sum \sum_{i \neq j=1}^{4} b_{i j} x_{i} x_{j}
$$

Em que:

$b_{\mathrm{o}}=$ constante,$b_{i}=$ coeficiente linear, $b_{i i}=$ coeficiente quadrático, $b_{i j}=$ coeficiente da interação, $x_{i} e$ $\mathrm{x}_{\mathrm{j}}=$ níveis das variáveis independentes e $\mathrm{Y}=$ variável dependente.

TABELA 1 - PLANEJAMENTO EXPERIMENTAL E VISCOSIDADE (PA.S) PARA OS TRATAMENTOS ANALISADOS

\begin{tabular}{|c|c|c|c|c|c|c|c|c|c|}
\hline \multirow{2}{*}{ Tratamento } & \multicolumn{4}{|c|}{ Valores codificados } & \multicolumn{4}{|c|}{ Valores reais (\%)1 } & \multirow{2}{*}{$\begin{array}{c}\text { Resposta } \\
\text { Viscosidade (Pa.s) }\end{array}$} \\
\hline & $x_{1}$ & $x_{2}$ & $x_{3}$ & $x_{4}$ & $x_{1}$ & $x_{2}$ & $x_{3}$ & $x_{4}$ & \\
\hline 1 & -1 & -1 & -1 & -1 & 1,00 & 0,40 & 0,07 & 0,07 & 15,87 \\
\hline 2 & -1 & -1 & -1 & 1 & 1,00 & 0,40 & 0,07 & 0,21 & 37,12 \\
\hline 3 & -1 & -1 & 1 & -1 & 1,00 & 0,40 & 0,21 & 0,07 & 35,50 \\
\hline 4 & -1 & -1 & 1 & 1 & 1,00 & 0,40 & 0,21 & 0,21 & 47,50 \\
\hline 5 & -1 & 1 & -1 & -1 & 1,00 & 0,80 & 0,07 & 0,07 & 25,50 \\
\hline 6 & -1 & 1 & -1 & 1 & 1,00 & 0,80 & 0,07 & 0,21 & 48,25 \\
\hline 7 & -1 & 1 & 1 & -1 & 1,00 & 0,80 & 0,21 & 0,07 & 26,12 \\
\hline 8 & -1 & 1 & 1 & 1 & 1,00 & 0,80 & 0,21 & 0,21 & 91,62 \\
\hline 9 & 1 & -1 & -1 & -1 & 2,00 & 0,40 & 0,07 & 0,07 & 12,25 \\
\hline 10 & 1 & -1 & -1 & 1 & 2,00 & 0,40 & 0,07 & 0,21 & 15,87 \\
\hline 11 & 1 & -1 & 1 & -1 & 2,00 & 0,40 & 0,21 & 0,07 & 24,00 \\
\hline 12 & 1 & -1 & 1 & 1 & 2,00 & 0,40 & 0,21 & 0,21 & 38,37 \\
\hline 13 & 1 & 1 & -1 & -1 & 2,00 & 0,80 & 0,07 & 0,07 & 44,75 \\
\hline 14 & 1 & 1 & -1 & 1 & 2,00 & 0,80 & 0,07 & 0,21 & 81,00 \\
\hline 15 & 1 & 1 & 1 & -1 & 2,00 & 0,80 & 0,21 & 0,07 & 106,30 \\
\hline 16 & 1 & 1 & 1 & 1 & 2,00 & 0,80 & 0,21 & 0,21 & 120,00 \\
\hline 17 & -2 & 0 & 0 & 0 & 0,50 & 0,60 & 0,14 & 0,14 & 25,00 \\
\hline 18 & 2 & 0 & 0 & 0 & 2,50 & 0,60 & 0,14 & 0,14 & 51,25 \\
\hline 19 & 0 & -2 & 0 & 0 & 1,50 & 0,20 & 0,14 & 0,14 & 26,50 \\
\hline 20 & 0 & 2 & 0 & 0 & 1,50 & 1,00 & 0,14 & 0,14 & 79,25 \\
\hline 21 & 0 & 0 & -2 & 0 & 1,50 & 0,60 & 0,00 & 0,14 & 22,00 \\
\hline 22 & 0 & 0 & 2 & 0 & 1,50 & 0,60 & 0,28 & 0,14 & 79,62 \\
\hline 23 & 0 & 0 & 0 & -2 & 1,50 & 0,60 & 0,14 & 0,00 & 5,38 \\
\hline 24 & 0 & 0 & 0 & 2 & 1,50 & 0,60 & 0,14 & 0,28 & 81,75 \\
\hline 25 & 0 & 0 & 0 & 0 & 1,50 & 0,60 & 0,14 & 0,14 & 68,60 \\
\hline 26 & 0 & 0 & 0 & 0 & 1,50 & 0,60 & 0,14 & 0,14 & 72,25 \\
\hline 27 & 0 & 0 & 0 & 0 & 1,50 & 0,60 & 0,14 & 0,14 & 51,75 \\
\hline
\end{tabular}




\section{RESULTADOS E DISCUSSÃO}

\subsection{VISCOSIDADE}

A Tabela 1 apresenta os resultados da determinação da viscosidade para os 27 tratamentos. Segundo ÜNAL, METIN e ISIKLI (2003) e KOKSOY e KILIC (2004) a viscosidade aparente é influenciada pela concentração de goma, teor de sólidos secos e pelo tipo de tratamento térmico, provavelmente pela compactação da rede de caseína. A Tabela 1 mostra que a viscosidade também variou conforme o teor de sólidos secos e o tipo de espessante empregado, sendo que quanto maior o teor de sólidos maior a viscosidade.

A máxima viscosidade (120,00 Pa.s) foi atingida no nível 1 de todas as variáveis, que representa $2,00 \%$ de leite em pó, $0,80 \%$ de gelatina e $0,21 \%$ de goma xantana e goma guar. Por outro lado, a mínima viscosidade (5,38 Pa.s) foi obtida no nível 0 de leite em pó, gelatina e goma xantana e no nível -2 de goma guar.

Pelo cálculo da análise de variância (ANOVA) observa-se que o $\mathrm{F}$ calculado $(18,31)$ é maior que o $\mathrm{F}$ tabelado $(2,49)$, ao nível de $95 \%$ de confiança, indicando a validade do modelo proposto para viscosidade (Tabela 2).

\section{TABELA 2 - ANÁLISE DE VARIÂNCIA (ANOVA) PARA O MODELO DE REGRESSÃO AJUSTADO DA VISCOSIDADE}

\begin{tabular}{llllll}
\hline Fonte & $\begin{array}{l}\text { Soma } \\
\text { Quad rática }\end{array}$ & $\begin{array}{l}\text { Graus de } \\
\text { Liberdade }\end{array}$ & $\begin{array}{l}\text { Média } \\
\text { Quad rática }\end{array}$ & F calculado & F tabelado \\
\hline Regressão & 22155,85 & 9 & 2461,76 & 18,31 & 2,49 \\
Resíduo & 2285,63 & 17 & 134,45 & & \\
Falta de Ajuste & 2046,47 & 15 & 136,43 & \\
Erro Puro & 239,17 & 2 & 119,58 & \\
Total & 24441,48 & 26 & & & \\
\hline
\end{tabular}

$R^{2}=0,9065 ;$ Nível de confiança $=95 \%$.

A equação ajustada pelo modelo de regressão (Tabela 3) para a viscosidade apresentou coeficiente de determinação de 0,9065 , isto é, $90,65 \%$ dos pontos obtidos experimentalmente são explicados pelo modelo.

\section{TABELA 3 - COEFICIENTES ESTIMADOS PELO MODELO DE REGRESSÃO AJUSTADO DA VISCOSIDADE}

\begin{tabular}{lllll}
\hline $\begin{array}{l}\text { Variáveis } \\
\text { Independentes }\end{array}$ & $\begin{array}{l}\text { Coeficiente de } \\
\text { Regress ão }\end{array}$ & Erro Puro & t-valor & p-valor \\
\hline Interceptação & 56,7542 & 3,6451 & 15,5699 & 0,0041 \\
Leite em pó (L) & 6,9817 & 2,2322 & 3,1277 & 0,0888 \\
Leite em pó (Q) & $-4,8255$ & 2,1613 & $-2,2327$ & 0,1552 \\
Gelatina (L)* & 17,6067 & 2,2322 & 7,8877 & 0,0157 \\
Goma Xantana (L)* & 13,5017 & 2,2322 & 6,0487 & 0,0263 \\
Goma Guar (L) & 14,2579 & 2,2322 & 6,3875 & 0,0236 \\
Goma Guar (Q) & $-3,4661$ & 2,1613 & $-1,6037$ & 0,2500 \\
Leite em pó X Gelatina* & 12,8788 & 2,7338 & 4,7109 & 0,0422 \\
Gelatina x Goma & 5,0175 & 2,7338 & 1,8353 & 0,2079 \\
Xantana & & & & \\
Gelatina x Goma Guar & 5,4350 & 2,7338 & 1,9880 & 0,1851 \\
\hline
\end{tabular}

\footnotetext{
* Estatisticamente significativo ao nível de 95\% de confiança. ** Estatisticamente significativo a 90\% de confiança.

***Estatisticamente significativo ao nível de $75 \%$ de confiança. $\mathrm{L}=$ linear. Q = quadrática.
} 
Os efeitos dos componentes que mais influenciaram a viscosidade foram gelatina, goma guar, goma xantana e a interação leite em pó - gelatina $(p<0,05)$. Para CÂNDIDO e CAMPOS (1995) a goma xantana e a goma guar apresentam sinergismo, sendo a viscosidade da mistura superior à soma das duas. Em contraste, neste estudo, a interação entre goma xantana e goma guar não foi significativa. Isso sugere que a interação da gelatina (proteína) com as gomas tenha diminuído o efeito da interação hidrocolóide - hidrocolóide, já que a interação proteína - hidrocolóide foi significativa. Segundo SCHMIDT e SMITH (1992), a interação entre proteínas e hidrocolóides influencia significativamente a viscosidade das soluções e varia conforme o tipo de goma e proteína utilizadas.

Os gráficos de contorno (Figuras 1, 2, 3, 4, 5 e 6) obtidos pela metodologia da superfície de resposta apresentam a mesma escala de viscosidade (Pa.s) para facilitar a interpretação e possibilitar sua comparação. Na construção dos gráficos de contorno as variáveis não-explicitadas estão fixadas em seu ponto central (nível 0).

\section{FIGURA 1 - GRÁFICO DE CONTORNO PARA OS EFEITOS DA CONCENTRAÇÃO DE LEITE EM PÓ E GELATINA (VALORES CODIFICADOS) NA VISCOSIDADE (PA.S)}

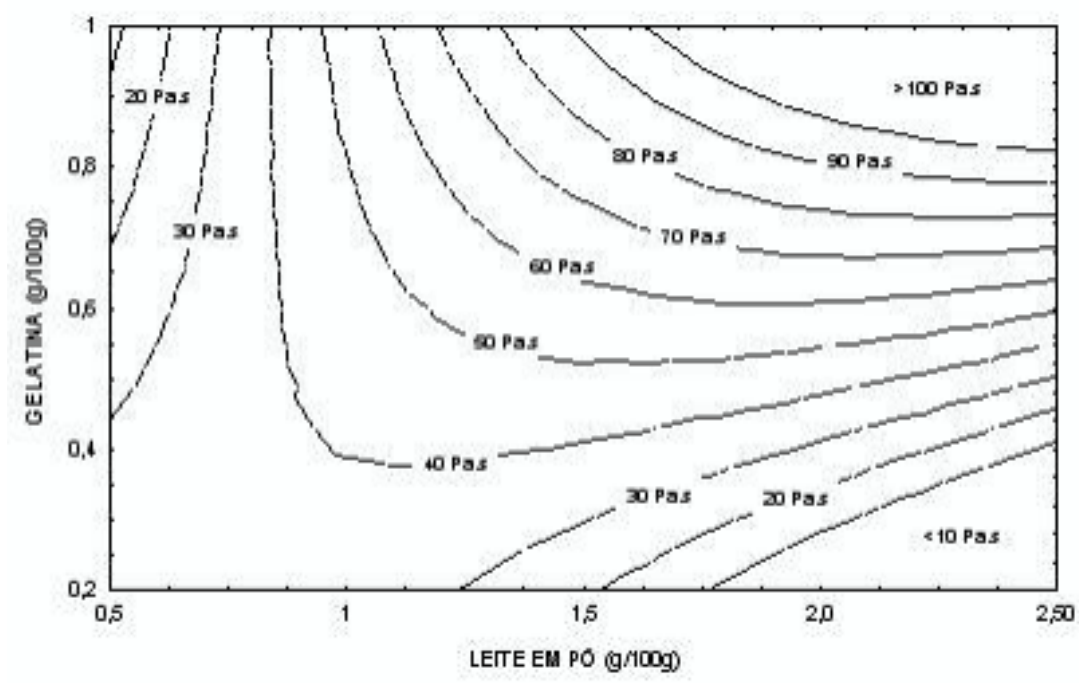

FIGURA 2 - GRÁFICO DE CONTORNO PARA OS EFEITOS DA CONCENTRAÇÃO DE LEITE EM PÓ E GOMA XANTANA (VALORES CODIFICADOS) NA VISCOSIDADE (PA.S)

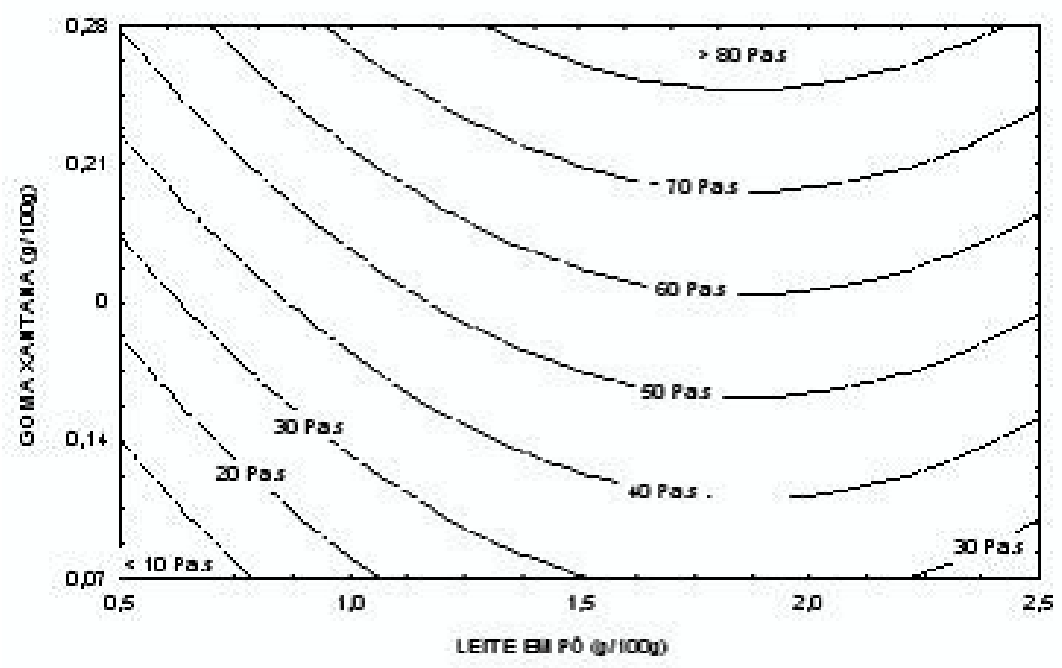


FIGURA 3 - GRÁFICO DE CONTORNO PARA OS EFEITOS DA CONCENTRAÇÃO DE LEITE EM PÓ E GOMA GUAR (VALORES CODIFICADOS)

NA VISCOSIDADE (PA.S)

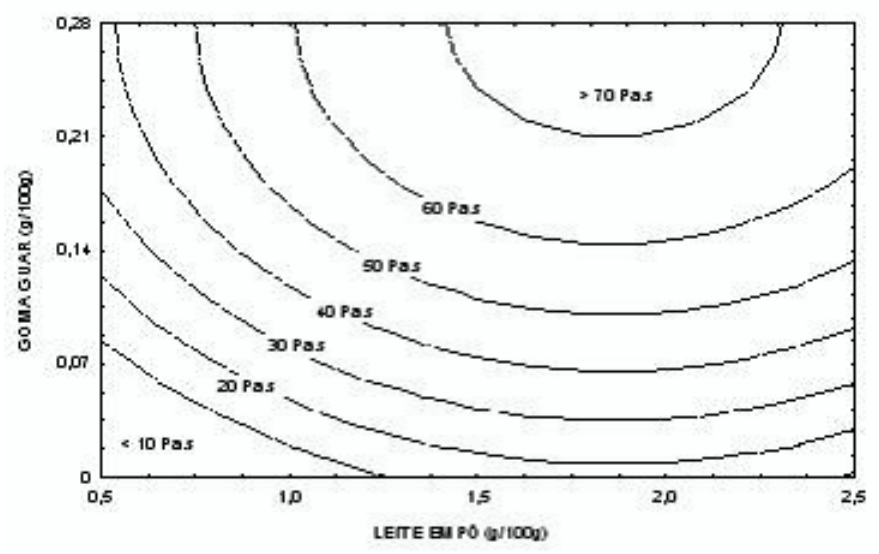

FIGURA 4 - GRÁFICO DE CONTORNO PARA OS EFEITOS DA CONCENTRAÇÃO DE GELATINA E GOMA XANTANA (VALORES CODIFICADOS) NA VISCOSIDADE (PA.S)

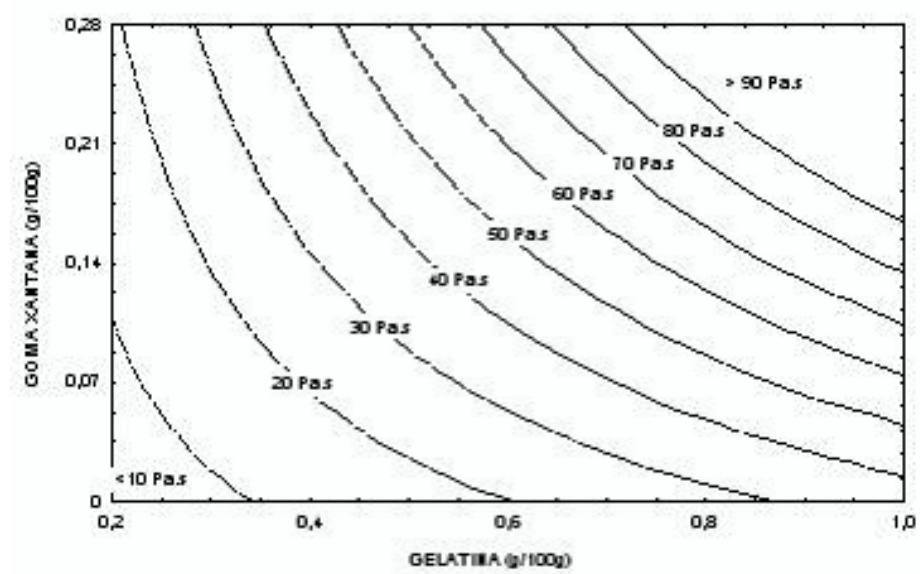

FIGURA 5 - GRÁFICO DE CONTORNO PARA OS EFEITOS DA CONCENTRAÇÃO DE GELATINA E GOMA GUAR (VALORES CODIFICADOS) NA VISCOSIDADE (PA.S)

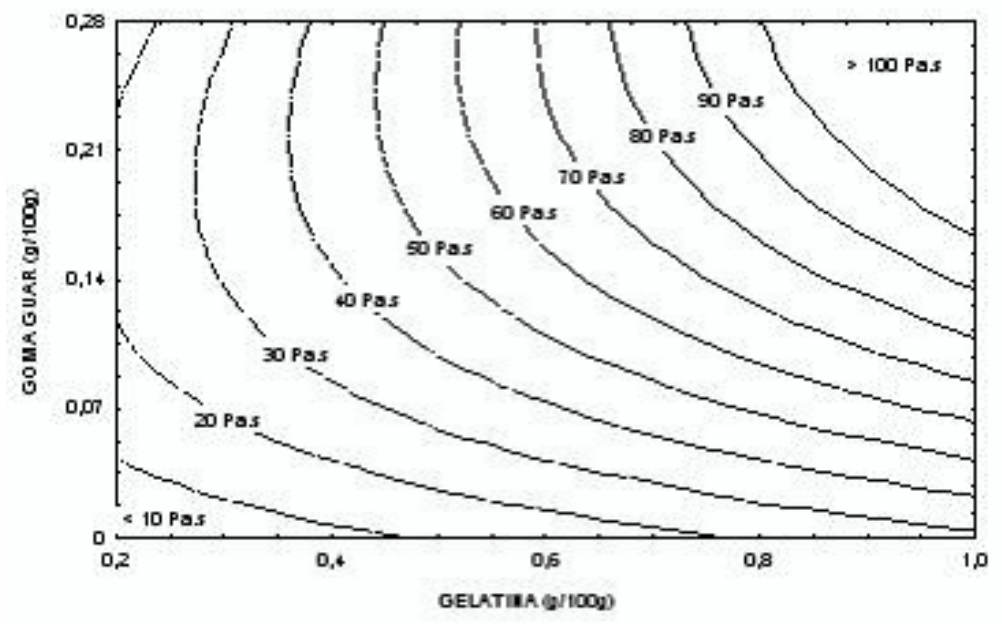




\section{FIGURA 6 - GRÁFICO DE CONTORNO PARA OS EFEITOS DA CONCENTRAÇÃO DE GOMA XANTANA E GOMA GUAR (VALORES CODIFICADOS) NA VISCOSIDADE (PA.S)}

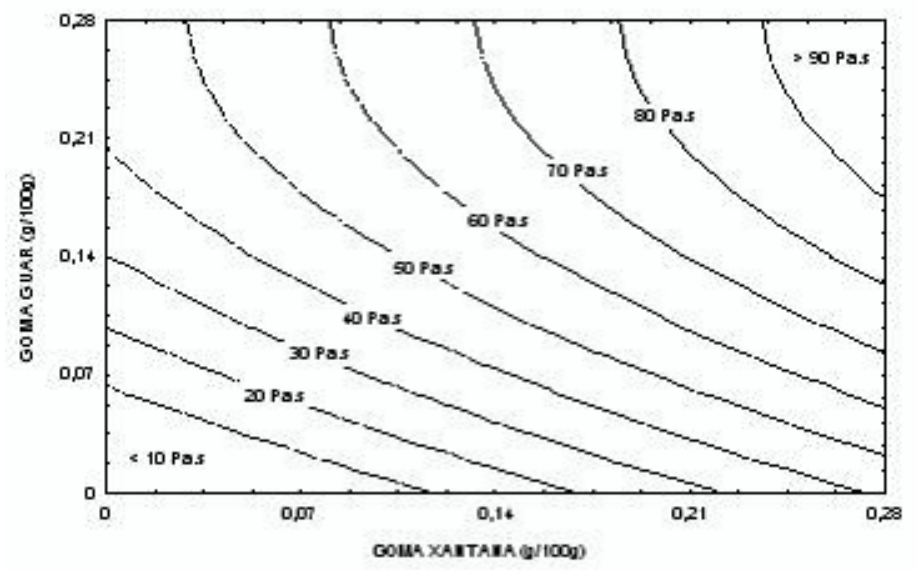

A variável leite em pó apresentou a menor influência na viscosidade do iogurte (Figuras 1, 2 e 3), o que é compreensível pelo fato dos outros três constituintes analisados serem espessantes e geleificantes.

\subsection{PARÂMETROS REOLÓGICOS}

A viscosidade aparente (Pa.s) dos iogurtes diminuiu com o aumento da taxa de deformação (1/s) (dados não-mostrados) indicando comportamento de fluido não Newtoniano, no qual a viscosidade permanece constante com a variação da taxa de deformação (BORWANKAR, 1992). A viscosidade aparente decresce devido ao rearranjo e/ou deformação das partículas, que resulta na diminuição da resistência ao escoamento (RAO, 1994). Alguns autores (PENNA, SIVIRI e OLIVEIRA, 2001; KOKSOY e KILIC, 2004) observaram que as bebidas lácteas fermentadas apresentam o mesmo tipo de comportamento. Além disso, relataram que o modelo da lei da potência tem sido utilizado na modelagem do comportamento do fluxo desse tipo de produto.

A partir dos resultados de taxa de deformação $(\dot{\gamma})$ e tensão de cisalhamento $(\sigma)$ (dados não-mostrados) obtiveram-se os parâmetros reológicos (Tabelas 4 e 5 ) tensão de cisalhamento inicial $\left(\sigma_{0}\right)$, índice de consistência $(K)$ e índice de comportamento reológico (n) dos 27 tratamentos.

\section{TABELA 4 - PARÂMETROS REOLÓGICOS DOS TRATAMENTOS TIPO HERSCHEL-BULKLEY}

\begin{tabular}{lllll}
\hline Tratamento & $\mathbf{\sigma}_{\mathbf{0}}(\mathbf{P a})$ & $\mathbf{K}(\mathbf{P a} \mathbf{s} \mathbf{)})$ & $\mathbf{n}$ & $\mathbf{R}^{2}$ \\
\hline 1 & 1,1503 & 0,0444 & 0,7335 & 0,976 \\
2 & 0,1203 & 2,3105 & 0,2874 & 0,992 \\
3 & 1,6042 & 0,9684 & 0,4536 & 0,999 \\
7 & 2,0760 & 0,1473 & 0,6018 & 0,984 \\
9 & 0,6441 & 0,2742 & 0,5002 & 0,999 \\
10 & 1,1482 & 0,1904 & 0,5466 & 0,980 \\
11 & 0,5162 & 1,2207 & 0,2600 & 0,990 \\
13 & 0,6105 & 2,5963 & 0,1944 & 0,995 \\
23 & 0,2680 & 0,1110 & 0,4981 & 0,999 \\
24 & 2,1614 & 2,5756 & 0,5714 & 0,966 \\
\hline
\end{tabular}

$\sigma_{\mathrm{o}}=$ tensão de cisalhamento inicial; $\mathrm{K}$ = coeficiente de consistência; $\mathrm{n}$ = índice de comportamento reológico. 


\section{TABELA 5 - PARÂMETROS REOLÓGICOS DOS TRATAMENTOS TIPO LEI DA POTÊNCIA (PSEUDOPLÁSTICOS)}

\begin{tabular}{llll}
\hline Tratamento & $\mathbf{K}\left(\mathbf{P a} \cdot \mathbf{s}^{\mathbf{n}}\right)$ & $\mathbf{n}$ & $\mathbf{R}^{\mathbf{2}}$ \\
\hline 4 & 2,8529 & 0,2076 & 0,972 \\
5 & 1,7103 & 0,2739 & 0,989 \\
6 & 3,9883 & 0,1680 & 0,963 \\
8 & 6,5666 & 0,1360 & 0,961 \\
12 & 2,6517 & 0,3039 & 0,986 \\
14 & 4,9074 & 0,2352 & 0,951 \\
15 & 7,2756 & 0,2173 & 0,892 \\
16 & 7,5826 & 0,1782 & 0,960 \\
17 & 1,5902 & 0,2599 & 0,979 \\
18 & 3,5827 & 0,1778 & 0,975 \\
19 & 1,7881 & 0,2601 & 0,978 \\
20 & 4,6587 & 0,3286 & 0,993 \\
21 & 1,4903 & 0,2926 & 0,979 \\
22 & 5,5856 & 0,1781 & 0,991 \\
25 & 3,4266 & 0,1824 & 0,988 \\
26 & 5,0009 & 0,1464 & 0,934 \\
27 & 3,7673 & 0,1919 & 0,980 \\
\hline
\end{tabular}

$\mathrm{K}=$ coeficiente de consistência; $\mathrm{n}$ = índice de comportamento reológico.

Alguns tratamentos (Tabela 4) apresentaram comportamento de fluido tipo Herschel-Bulkley $\left(\left(\sigma-\sigma_{0}\right)=K \cdot \dot{\gamma}^{n}\right)$, necessitando de tensão de cisalhamento inicial $\left(\sigma_{0}\right)$ para começar a escoar e outros comportamento pseudoplástico (Tabela 5) $\left(\sigma=K \cdot \dot{\gamma}^{n}\right)$. Segundo BENEZECH e MAINGONNAT (1994), LORENZI, PRICL e TORRIANO (1995) e PENNA, SIVIERI e OLIVEIRA (2001), o iogurte natural integral é fluido pseudoplástico. Os coeficientes de determinação $\left(R^{2}\right)$ (Tabelas 4 e 5) dos tratamentos variou entre 0,966 e 0,999 para fluidos tipo Herschel-Bulkley e entre 0,892 e 0,993 para fluidos que seguem a lei da potência com $n>1$, portanto pseudoplásticos.

A comparação dos parâmetros reológicos é mais clara quando se analisam os pontos axiais (tratamentos 17 - 24), níveis -2 e +2 de cada variável, pois assim as outras permanecem constantes no nível 0 . Observa-se que os tratamentos 17 e 18, pontos axiais da variável leite em pó, apresentaram comportamento pseudoplástico, sendo que o índice de consistência aumentou de 1,5902 para 3,5827 com a elevação do nível da variável de $-2(0,5 \%)$ para $2(2,5 \%)$. A relação também acontece com as variáveis gelatina (tratamentos 19 e 20) e goma xantana (tratamento 21 e 22). Entretanto, os pontos axiais da goma guar apresentaram comportamento Herschel-Bulkley e igualmente o aumento da concentração elevou o índice de consistência. BOURRIOT, GARNIER e DOUBLIER (1999) e SCHMIDT e SMITH (1992) reportaram que a goma guar em combinação com as proteínas do leite exibe comportamento não-Newtoniano, já em soluções aquosas e em baixas concentrações a goma guar apresenta-se como fluido Newtoniano.

Quanto menor o valor do índice de comportamento reológico (n) em relação a um maior será a pseudoplasticidade, e quanto maior o valor de $\mathrm{n}$ em relação a um mais características dilatantes apresenta o fluido. $O$ índice de consistência ( $k$ é interpretado como espessamento relativo, sendo que quanto maior o $\mathrm{k}$ maior é a aceitabilidade do iogurte (PENNA, SIVIERI e OLIVEIRA, 2001).

A análise dos valores do índice de comportamento reológico das variáveis leite em pó (tratamentos 17 e 18) e goma xantana (tratamentos 21 e 22) indica que quanto maior a concentração desses maior a pseudoplasticidade (já que os valores de $\mathrm{n}$ diminuem), fato também observado por SCHMIDT e SMITH (1992) para goma xantana. Segundo KOKSOY e KILIC (2004), a redução do índice de comportamento reológico do ayran com o aumento da concentração de estabilizantes pode ser explicada pela orientação das moléculas dos estabilizantes sob tensão. 
O índice de comportamento reológico dos pontos axiais da gelatina aumentou de 0,2601 para 0,3286 com a elevação de sua concentração de $0,2 \%$ para $1 \%$, demonstrando diminuição da pseudoplasticidade e aumento na tendência do iogurte apresentar características Newtonianas. MARCOTTE, HOSHAHILI e RAMASWAMY (2001) relataram que soluções aquosas de gelatina com 1, 2 e 3\% têm comportamento Newtoniano. Já comparando os tratamentos 23 e 24 nota-se que quanto maior a concentração de goma guar maior a tensão de cisalhamento inicial para o fluido começar a escoar.

\section{CONCLUSÃO}

Neste trabalho mostrou-se que quanto maior o teor de sólidos maior a viscosidade, entretanto, os limites definidos pela legislação e a consistência característica do iogurte natural devem ser observados. A gelatina apresentou maior influência sobre a viscosidade do iogurte natural desnatado, seguida pela goma guar, goma xantana e leite em pó. As interações significativas foram gelatina $x$ leite em pó, gelatina $x$ goma guar e gelatina $x$ goma xantana. Também foi observado que algumas formulações apresentaram comportamento de fluido tipo Herschel-Bulkley e outras tipo pseudoplástico.

\section{ABSTRACT}

\section{THE INFLUENCE OF THE ADDITION OF STABILIZERS AND SKIM MILK POWDER ON THE RHEOLOGICAL PROPERTIES OF NON-FAT YOGHURT}

The demand for reduced fat content milky products has increased due to the conscience of the harmful effects of fat on human health. However, the non-fat yoghurt presents low viscosity, being recommended the use of thickening to confer and keep the desirable characteristics of texture and body. In this work it was employed the response surface methodology to study the influence of skim milk powder, gelatin, xanthan gum and guar gum addition on the rheological properties of non-fat yoghurt. The variables that most influenced viscosity were gelatin, guar gum, xanthan gum and the interaction skim milk powder gelatin $(p<0,05)$, respectively. Moreover, some treatments behaved as Herschel-Bulkley fluid and others as pseudoplastic fluid.

\section{KEY-WORDS: NON-FAT YOGHURT; RHEOLOGICAL PROPERTIES; RESPONSE SURFACE METHODOLOGY.}

\section{REFERÊNCIAS}

$1 \mathrm{AKOH}, \mathrm{C.C.}$ Fat replacer. Food Technology, Chicago, v.52, p.47-53, 1998.

2 ANCOS, B.; CANO, M.P.; GÓMEZ, R. Characteristics of stirred low-fat yoghurt as affected by high pressure. International Dairy Journal, v.10, p.105-111, 2000.

3 BENEZECH, I.; MAINGONNAT, J.F. Characterization of the rheological properties of yogurt - a review. Journal of Food Engineering, v.21, p.447-472, 1994.

4 BORWANKAR, R.P. Food texture and rheology: a tutorial review. In: BORWANKAR, R.P.; SHOEMAKER, C.E. (ed.). Rheology of foods. London: Elsevier Applied Science, 1992. p.1-16.

5 BOURRIOT, S.; GARNIER, C.; DOUBLIER, J.L. Phase separation, rheology and structure of micellar caseingalactomannan mixture. International Dairy Journal, v.9, n.3-6, p.353-357, 1999.

6 BRASIL. Ministério da Agricultura, Pecuária e Abastecimento. Resolução n. ${ }^{\circ}$ 5, de novembro de 2000. Disponível em: http:/ loc4j.agricultura.gov.br/agrolegis/do/consultaLei?op=viewTextual\&codigo=3285. Acesso em: 05 nov. 2004.

7 BROOKFIELD ENGINEERING LABORATORIES. Brookfield Digital Viscometer - Model DV-I+ - Operating Instructions. Massachusetts, 1992. (Manual No. M/92-021-0604.)

8 CÂNDIDO, L.M.B.; CAMPOS, A.M. Alimentos para fins especiais: dietéticos. São Paulo: Varela, 1995. 423 p. 
9 EL-SAYED, E.M.; ABD EL-GAWAD, I.A.; MURAD, H.A.; SALAH, S.H. Utilization of laboratory-produced xanthan gum in the manufacture of yogurt and soy yogurt. Europe Food Research Technology, v.215, p.298-304, 2002.

10 EVERETT, D.W.; MCLEOD, R.E. Interactions of polysaccharide stabilisers with casein aggregates in stirred skim-milk yoghurt. International Dairy Journal, v.15, p.1175-1183, 2005.

11 FOLKENBERG, D.M.; DEJMEK, P.; SKIYERB, A.; GULDAGER, H.S.; IPSENA, R. Sensory and rheological screening of exopolysaccharide producing strains of bacterial yoghurt cultures. International Dairy Journal, v.16, p.111-118, 2006.

12 HYAMS, D. Curve Expert. Version 1.3 (software). Hixton, 1997.

13 KOKSOY, A.; KILIC, M. Use of hydrocolloids in textural stabilization of a yoghurt drink, ayran. Food Hydrocolloids, v.18, p.593-600, 2004.

14 LANCIOTTI, R.; VANNINI, L.; PITTIA, P.; GUERZONI, M.E. Suitability of high-dynamic-pressure-treated milk for the production of yoghurt. Food Microbiology, v.21, p.753-760, 2004.

15 LORENZI, D.L.; PRICL, S.; TORRIANO, G. Rheological behavior of low-fat and full-fat stirred yogurt. International Dairy Journal, v.5, p.661-671, 1995.

16 LUCEY, J. A.; MUNRO, P. A.; SINGH, H. Effects of heat treatment and whey protein addition on the rheological properties and structure of acid skim milk gels. International Dairy Journal, v.9, n.3-6, p.275-279, 1999.

17 MARCOTTE, M.; HOSHAHILI, A.R.T.; RAMASWAMY, H.S. Rheological properties of selected hydrocolloids as a function of concentration and temperature. Food Research International, v.34, p.695-703, 2001.

18 PENNA, A.L.B.; SIVIERI, K.; OLIVEIRA, M.N. Relation between quality and rheological properties of lactic beverages. Journal of Food Engineering, v.49, p.7-13, 2001.

19 RAO, M.A. Rheological properties of fluid foods. In: RAO, M.A.; RIZVI, S.S. (ed.). Engineering properties of foods. $2^{\text {nd }}$ ed. New York: Marcel Dekker, 1994. p.1-53.

20 RUAS-MADIEDO, P.; ZOON, P. Effect of exopolysaccharide-producing Lactococcus lactis strains and temperature on the permeability of skim milk gels. Colloids and Surfaces A: Physicochemical Engineering Aspects, v.213, p.245-253, 2003.

21 SCHMIDT, K.A.; SMITH, D.E. Rheological properties of gum and milk protein interactions. Journal of Dairy Science, v.75, n.1, p.36-42, 1992.

22 TRONCO, V.M. Manual para inspeção da qualidade do leite. Santa Maria: Editora UFSM, 1997. 166 p

23 ÜNAL, B.; METIN, S.; ISIKLI, N.D. Use of response surface methodology to describe the combined effect of storage time, locust bean gum and dry matter of milk on the physical properties of low-fat set yoghurt. International Dairy Journal, v.13, p.909-916, 2003. 